\title{
ATTENUATION OF LOVE AND RAYLEIGH WAVES ACROSS THE ATLANTIC
}

\author{
José A. CANaS \\ Department of Earth and Atmospheric Sciences, \\ Saint Louis University, Saint Louis, Mo, U.S.A., \\ and Cátedra de Geofisica, Universidad Complutense \\ de Madrid, Madrid, 3, Spain
}

(Received December 3, 1980)

\begin{abstract}
Using the two-station-method, average fundamental mode surface-wave velocities and attenuation coefficients have been determined in the Atlantic Ocean. The average Rayleigh-wave attenuation coefficients decrease from $3.04 \times 10^{-4} \mathrm{~km}^{-1}$ at a period of $15 \mathrm{sec}$ to about $0.40 \times 10^{-4} \mathrm{~km}^{-1}$ at the longer periods. The average Love-wave attenuation coefficients, in the period range 26 to $100 \mathrm{sec}$, vary from a value of about $2.20 \times 10^{-4} \mathrm{~km}^{-1}$ at the shorter periods to a minimum value of $0.92 \times 10^{-4} \mathrm{~km}^{-1}$ at the longest period.

Backus-Gilbert inversion theory applied to the attenuation data yields an average $Q_{\beta}^{-1}$ model for the Atlantic that shows a clear and well-developed low- $Q$ zone situated approximately between 40 and $220 \mathrm{~km}$ depth. The maximum $Q_{\beta}^{-1}$ value $\left(\sim 13 \times 10^{-3}\right)$ occurs at $100 \mathrm{~km}$ depth.
\end{abstract}

\section{Introduction}

Extensive use of seismic surface-wave velocities has provided good knowledge of the regional elastic properties in the Pacific Ocean (e.g., LeEDS et al., 1974; KAUSEL et al., 1974; Forsyth, 1975 a, 1975 b; Yoshir, 1975; YU and MrTCHeLl, 1979; Canas and Udias, 1980). The observed surface wave velocities obtained in these studies generally increase with increasing age and thickness of the oceanic lithosphere.

Fewer studies of attenuation of seismic surface waves have been carried out in the Pacific, especially due to the difficulty in obtaining good amplitude data. TSAI and AKI (1969), using a single event, determined attenuation of surface waves in the period range of 15 to $50 \mathrm{sec}$. Mrtchell et al. (1976) obtained average attenuation coefficients for Rayleigh- and Love-waves in a broad region of that ocean. Mrtchell (1976) determined internal friction models using observed attenuation coefficients (MrTCHeLl et al., 1976), the best model being the one obtained from only Rayleigh-wave attenuation coefficients. CANAS and MrTCHELL (1978) determined regionalized Rayleigh-wave attenuation coefficients and shearwave internal friction for three regions of the Pacific plate, showing that the attenuation and internal friction are functions of the oceanic age, with the attenuation values being higher for younger oceanic regions. CANAS et al. (1980) 
determined internal friction models for the East Pacific Rise and the Nazca plate. The results indicate that the internal friction under the East Pacific Rise and the Nazca plate is much higher than the corresponding one in the region $0-50 \mathrm{~m} . \mathrm{y}$. of the Pacific plate.

Fewer studies of surface wave velocities and attenuation have been carried out in the Atlantic Ocean. OssiNG (1964), using group velocity dispersion curves from earthquakes in the Mid-Atlantic Ridge, deduced that the Mid-Atlantic Ridge had little influence on the dispersion of Rayleigh waves. Results obtained by BRAvo and UDIAS (1974) from Rayleigh wave group velocity observations agree with those of OSSING (1964). WEIDNER (1974) and GIRARDIN and JACOBY (1979), using phase and group velocities from paths nearly parallels to the MidAtlantic Ridge, found that the influence of the ridge is to decrease the observed velocities. Attenuation studies include that of BeN-MENAHEM (1965) who obtained attenuation values for Love and Rayleigh waves in the period range 50-330 sec for mixed paths across oceans and continents. ANDERSON et al. (1965) obtained specific quality factors of Rayleigh waves for a single path across the Atlantic. Solomon (1973), using shear-wave amplitudes, found evidence for a narrow low- $Q$ zone under the Mid-Atlantic Ridge.

The purpose of the present study is to obtain representative averages of the Rayleigh- and Love-wave attenuation coefficients in the Atlantic Ocean. Inversion theory (BACKus and GilbERT, 1967, 1968, 1970) in its stochastic form (DER et al., 1970; JORDAN and FRANKLIN, 1971) applied to the Rayleigh-wave attenuation data yields an average internal friction model of shear waves for this ocean.

\section{Data Analysis}

The two-station-method has been applied to 28 events and 12 seismograph stations (Table 1, Fig. 1), situated on the American and European coastal regions and on islands in the Atlantic Ocean, to determine fundamental mode Rayleighwave attenuation coefficients for the Atlantic Ocean. Love wave attenuation coefficients have been obtained using 9 events and 7 seismograph stations (Table 1, Fig. 1).

Spectral amplitudes of the fundamental modes of Rayleigh and Love waves as a function of period and group velocity were obtained from the vertical component of Rayleigh waves and from the transverse component of Love waves; the transverse component being calculated using a coordinate transformation of the North-South and East-West components. All the seismograph stations belong to the WWSSN system, except two that belong to the Canadian network. Departures from expected amplitude responses of the WWSSN system can be checked by comparing daily calibration pulses with theoretical responses (MrTCHELL and Landisman, 1969). Magnification curves for the Canadian network can be obtained from the Seismological Bulletin of the Dominion Observatory of Ottawa (Canada). 
Table 1. Earthquakes and stations used for velocity, attenuation and specific quality factor determinations.

\begin{tabular}{|c|c|c|c|c|c|c|}
\hline \multicolumn{3}{|c|}{ Date } & Location & \multirow{2}{*}{$\frac{\text { Origin time }}{6: 50: 58.2}$} & \multirow{2}{*}{$\begin{array}{c}\begin{array}{c}\text { Stations used for } \\
\text { Rayleigh waves }\end{array} \\
\text { PTO-TRN }\end{array}$} & \multirow[t]{2}{*}{$\begin{array}{l}\text { Stations used for } \\
\text { Love waves }\end{array}$} \\
\hline 2 & Nov & 64 & $4.1 \mathrm{~S}, 76.9 \mathrm{~W}$ & & & \\
\hline 28 & Nov & 66 & $6.7 \mathrm{~N}, 82.6 \mathrm{~W}$ & $7: 32: 53.6$ & PDA-SJG & \\
\hline 26 & Jan & 67 & $14.9 \mathrm{~N}, 93.0 \mathrm{~W}$ & $16: 10: 33.7$ & BEC-PTO & BEC-PTO \\
\hline 19 & Apr & 68 & $42.6 \mathrm{~S}, \quad 16.0 \mathrm{~W}$ & $9: 04: 27.3$ & HAL-NAT & \\
\hline 15 & Jun & 68 & $5.6 \mathrm{~N}, 82.6 \mathrm{~W}$ & $7: 08: 48.1$ & PTO-SJG, PDA-SJG & BEC-PTO \\
\hline 29 & Dec & 68 & $14.5 \mathrm{~N}, \quad 92.4 \mathrm{~W}$ & $17: 36: 29.9$ & & BEC-PTO \\
\hline 7 & Jul & 68 & $5.8 \mathrm{~S}, \quad 77.1 \mathrm{~W}$ & $23: 48: 08.2$ & PDA-TRN & \\
\hline 4 & Feb & 69 & $8.2 \mathrm{~S}, \quad 80.2 \mathrm{~W}$ & $4: 10: 13.3$ & PDA-TRN & \\
\hline 4 & Apr & 69 & $24.4 \mathrm{~N}, 109.8 \mathrm{~W}$ & $16: 16: 17.2$ & OGD-PTO & \\
\hline 5 & May & 69 & $36.0 \mathrm{~N}, \quad 10.4 \mathrm{~W}$ & $5: 34: 23.5$ & BEC-PDA & \\
\hline 24 & Jul & 69 & $11.9 \mathrm{~S}, \quad 75.1 \mathrm{~W}$ & $2: 59: 21.0$ & $\begin{array}{l}\text { AKU-SJG, AKU-CAR } \\
\text { TRN-VAL }\end{array}$ & \\
\hline 20 & Oct & 69 & $10.8 \mathrm{~N}, \quad 72.5 \mathrm{~W}$ & $13: 11: 37.0$ & SJG-VAL & \\
\hline 21 & Jan & 70 & $7.0 \mathrm{~N}, 104.3 \mathrm{~W}$ & $17: 51: 38.5$ & & BEC-PTO \\
\hline 14 & Feb & 70 & $9.9 \mathrm{~S}, \quad 75.6 \mathrm{~W}$ & $11: 17: 16.1$ & TRN-VAL, AKU-CAR & \\
\hline 1 & Jun & 70 & $5.9 \mathrm{~N}, \quad 82.5 \mathrm{~W}$ & $17: 44: 15.0$ & PDA-SJG, PTO-SJG & \\
\hline 16 & Jun & 70 & $5.4 \mathrm{~N}, 82.5 \mathrm{~W}$ & $5: 10: 33.0$ & PDA-SJG, PTO-SJG & \\
\hline 17 & Jun & 70 & $15.8 \mathrm{~S}, \quad 71.8 \mathrm{~W}$ & $4: 44: 20.9$ & AKU-TRN & \\
\hline 30 & Jun & 70 & $9.2 \mathrm{~S}, \quad 79.0 \mathrm{~W}$ & $6: 21: 03.9$ & PTO-TRN & PTO-TRN \\
\hline 27 & Aug & 70 & $15.4 \mathrm{~N}, \quad 95.6 \mathrm{~W}$ & $19: 44: 42.0$ & BEC-PTO & \\
\hline 26 & Oct & 70 & $79.8 \mathrm{~N}, \quad 2.7 \mathrm{~W}$ & $20: 53: 32.4$ & AKU-NAT & \\
\hline 3 & Dec & 70 & $7.4 \mathrm{~N}, \quad 76.1 \mathrm{~W}$ & $4: 59: 53.4$ & SJG-VAL & \\
\hline 14 & Dec & 70 & $1.3 \mathrm{~S}, \quad 80.9 \mathrm{~W}$ & $7: 32: 52.5$ & SJG-VAL & \\
\hline 19 & Sep & 72 & $19.5 \mathrm{~N}, \quad 70.1 \mathrm{~W}$ & $1: 36: 52.4$ & STJ-AKU & \\
\hline 3 & $\mathrm{Apr}$ & 73 & $4.7 \mathrm{~N}, \quad 75.6 \mathrm{~W}$ & $13: 54: 01.8$ & & SJG-VAL \\
\hline 24 & Apr & 73 & $5.2 \mathrm{~N}, \quad 75.8 \mathrm{~W}$ & $18: 42: 31.9$ & & SJG-VAL \\
\hline 16 & Sep & 73 & $5.2 \mathrm{~N}, 78.0 \mathrm{~W}$ & $4: 52: 50.9$ & SJG-VAL & SJG-VAL \\
\hline 3 & Oct & 73 & $27.6 \mathrm{~N}, 112.4 \mathrm{~W}$ & $4: 27: 40.5$ & STJ-PTO & OGD-PDA \\
\hline 27 & Apr & 74 & $15.0 \mathrm{~S}, \quad 72.2 \mathrm{~W}$ & $6: 01: 47.3$ & AKU-TRN & \\
\hline 9 & Jun & 74 & $5.8 \mathrm{~S}, \quad 81.0 \mathrm{~W}$ & $14: 16: 03.7$ & PTO-TRN & \\
\hline 18 & Mar & 75 & $10.1 \mathrm{~S}, \quad 75.3 \mathrm{~W}$ & $1: 10: 53.6$ & TRN-VAL & \\
\hline 5 & Apr & 75 & $10.0 \mathrm{~N}, \quad 69.8 \mathrm{~W}$ & $9: 34: 36.6$ & AKU-SJG & \\
\hline 21 & Nov & 75 & $7.5 \mathrm{~N}, \quad 77.6 \mathrm{~W}$ & $1: 15: 00.8$ & PTO-SJG & \\
\hline
\end{tabular}

A constant interval of $1.0 \mathrm{sec}$, obtained applying a linear interpolation to the irregularly digitized seismograms, was chosen to carry out the multiple filter analysis (DzIEwonski et al., 1969; HerrmanN, 1973). To avoid, as much as possible, scatter in the amplitude data, only events with departures of less than 4 azimuthal degrees from the common great-circle path with two seismograph stations have been used. To minimize the effects due to the waves crossing oceanic-continental margins, stations were chosen situated on islands and on coastal regions of the Atlantic. It was also tried to avoid problems due to the interference of the fundamental mode by the higher ones. This effect is much more 


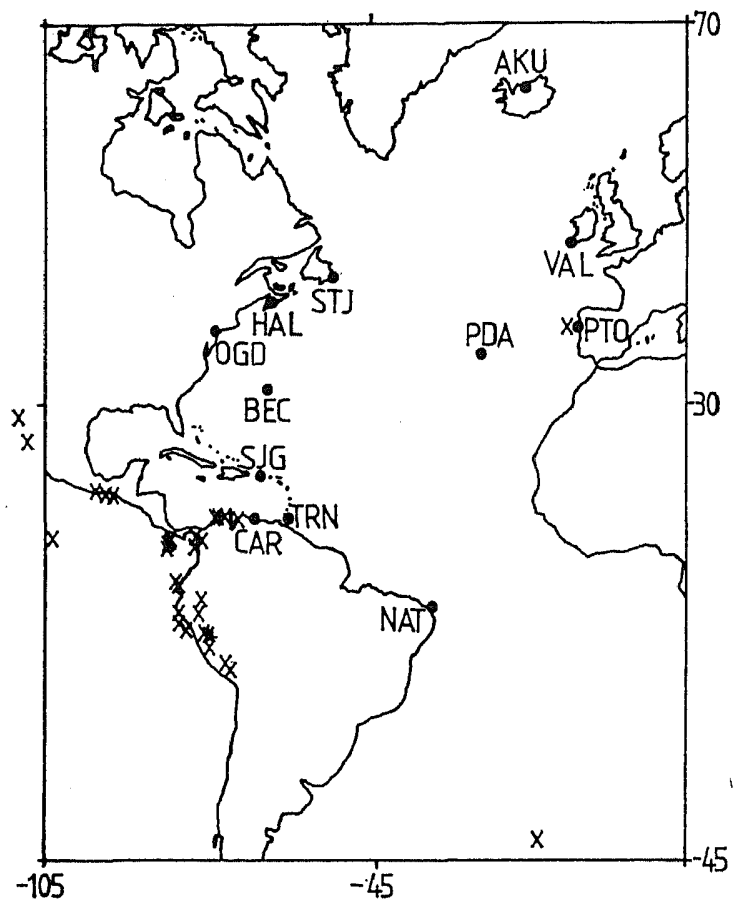

Fig. 1. Mercator projection map of the Atlantic, including the location of epicenters $(x)$ and stations $(\bullet)$.

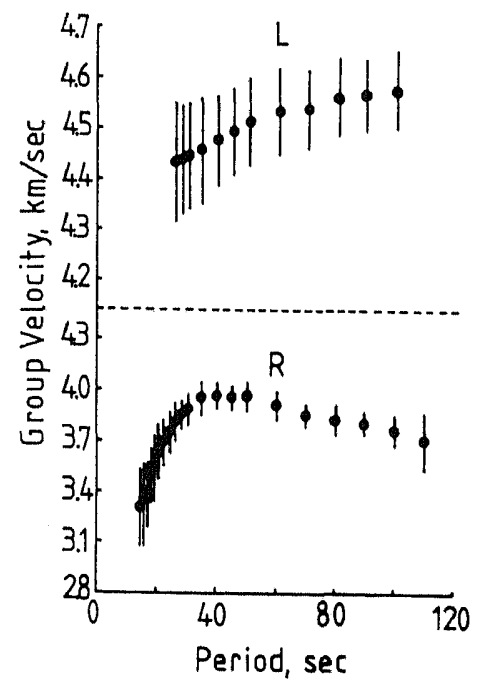

Fig. 2. Average observed Rayleigh and Love wave group velocities in the Atlantic Ocean. Vertical bars indicate standard deviations. 
important for Love than for Rayleigh waves. DRAKE and BOLT (1980) have shown that there is more energy associated with the higher modes of Love waves than with the fundamental mode for periods equal to or less than $30 \mathrm{sec}$. Therefore, it may be possible that Love wave amplitude data at periods of around $30 \mathrm{sec}$ may be contaminated by higher mode energy. The Rayleigh and Love observed group velocities (Fig. 2) are oceanic in character, being close to the $8-1-2$ and 8-3-2 oceanic models of SAITO and TAKEUCHI (1966) respectively.

\section{Average Attenuation Coefficients}

The attenuation coefficients of surface waves, using the two-station method, are given by,

$$
\gamma(\omega)=\left\{\ln \frac{A_{1}\left(\omega, r_{1}\right) I_{2}(\omega)\left(\sin \Delta_{1}\right)^{1 / 2}}{A_{2}\left(\omega, r_{2}\right) I_{1}(\omega)\left(\sin \Delta_{2}\right)^{1 / 2}}\right\} /\left(r_{2}-r_{1}\right)
$$

where $\gamma((1))$ is the attenuation coefficient as a function of angular frequency $\omega$. $A_{1}$ and $A_{2}$ are the spectral amplitudes corresponding to the stations situated at shorter and longer distances $\left(r_{1}, r_{2}\right)$. $I_{1}$ and $I_{2}$ are the instrumental responses of the seismographs and $\left(\sin A_{1}\right)^{1 / 2}$ and $\left(\sin \Delta_{2}\right)^{1 / 2}$ correct for geometrical spreading of the energy.

Table 2. Rayleigh- and Love-wave group velocities, attenuation coefficients, and specific quality factors for the Atlantic Ocean.

\begin{tabular}{|c|c|c|c|c|c|c|}
\hline$T$ & $U_{11}(\mathrm{~km} / \mathrm{sec})$ & $\gamma_{\mathrm{n}}\left(10^{-1} \mathrm{~km}^{-1}\right)$ & $Q_{n}$ & $U_{\mathrm{L}}(\mathrm{km} / \mathrm{sec})$ & $r_{\mathrm{L}} \times\left(10^{-1} \mathrm{~km}^{-1}\right)$ & $Q_{\mathrm{L}}$ \\
\hline 15 & $3.307+0.235$ & $3.04+1.26$ & 208 & & & \\
\hline 16 & $3.358 \quad 0.212$ & $2.63 \quad 1.01$ & 222 & & & \\
\hline 17 & $3.384 \quad 0.188$ & $2.27 \quad 0.93$ & 240 & & & \\
\hline 18 & $3.494 \quad 0.162$ & $2.13 \quad 1.07$ & 233 & & & \\
\hline 19 & $3.539 \quad 0.194$ & $1.90 \quad 1.12$ & 245 & & & \\
\hline 20 & $3.629 \quad 0.161$ & $1.83 \quad 1.13$ & 236 & & & \\
\hline 22 & $3.695 \quad 0.144$ & $1.75 \quad 1.00$ & 220 & & & \\
\hline 24 & $3.752 \quad 0.125$ & $1.77 \quad 0.98$ & 196 & & & \\
\hline 26 & $3.810 \quad 0.113$ & $1.64 \quad 1.00$ & 193 & $4.438+0.121$ & $2.21 \pm 1.78$ & 123 \\
\hline 28 & $3.853 \quad 0.095$ & $1.58 \quad 0.91$ & 183 & $4.446 \quad 0.106$ & $2.18 \quad 1.61$ & 116 \\
\hline 30 & $3.883 \quad 0.090$ & $1.60 \quad 0.79$ & 168 & $4.450 \quad 0.103$ & $2.26 \quad 1.66$ & 104 \\
\hline 35 & $3.951 \quad 0.100$ & $1.70 \quad 0.81$ & 133 & $\begin{array}{ll}4.462 & 0.099\end{array}$ & $1.98 \quad 1.47$ & 102 \\
\hline 40 & 3.9620 .077 & $\begin{array}{ll}1.56 & 0.82\end{array}$ & 127 & $4.485 \quad 0.089$ & $1.71 \quad 0.94$ & 102 \\
\hline 45 & $3.952 \quad 0.067$ & $1.39 \quad 0.81$ & 126 & $4.502 \quad 0.086$ & $1.65 \quad 1.03$ & 94 \\
\hline 50 & $3.964 \quad 0.086$ & $1.36 \quad 0.83$ & 115 & $4.528 \quad 0.086$ & $1.43 \quad 0.96$ & 97 \\
\hline 60 & $3.912 \quad 0.086$ & $1.24 \quad 0.54$ & 107 & $4.539 \quad 0.082$ & 1.210 .98 & 95 \\
\hline 70 & $3.856 \quad 0.060$ & $1.01 \quad 0.29$ & 114 & $4.540 \quad 0.073$ & $1.43 \quad 0.91$ & 69 \\
\hline 80 & $3.830 \quad 0.086$ & $0.94 \quad 0.27$ & 108 & $4.575 \quad 0.074$ & $1.34 \quad 1.13$ & 64 \\
\hline 90 & $3.808 \quad 0.058$ & $0.58 \quad 0.30$ & 156 & $4.580 \quad 0.065$ & $1.24 \quad 1.03$ & 62 \\
\hline 100 & $3.766 \quad 0.090$ & $0.38 \quad 0.48$ & 218 & $4.584 \quad 0.072$ & $0.92 \quad 0.52$ & 75 \\
\hline 110 & $3.711 \quad 0.176$ & $0.43 \quad 0.08$ & 176 & & & \\
\hline
\end{tabular}




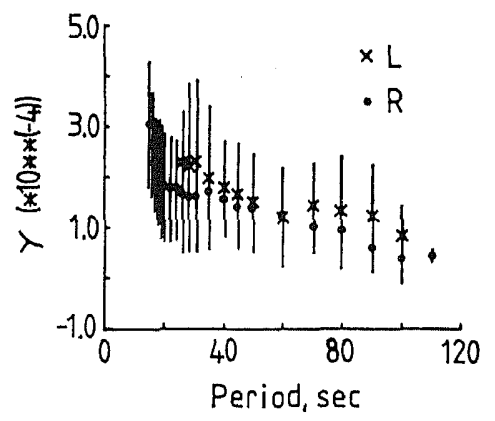

Fig. 3. Average observed Rayleigh- and Love-wave attenuation coefficients in the Atlantic Ocean. Vertical bars indicate standard deviations.

Table 2 lists the average Atlantic attenuation coefficients for Rayleigh and Love waves together with the observed inter-station group velocities and corresponding specific quality factors of Rayleigh and Love waves $\left(Q_{\mathrm{R}}, Q_{\mathrm{L}}\right)$. $Q$ values were determined using the expression $Q=\pi / \gamma U T$, where $U$ is the group velocity as a function of the period $T$. Figure 3 presents the average Rayleigh- and Lovewave attenuation coefficients as a function of the period together with their standard deviations. It can be observed (Fig. 3), that the attenuation coefficients decrease with decreasing frequency.

\section{Average Internal Friction Model}

Using inversion theory (BACKUS and GILBERT, 1967, 1968, 1970) in its stochastic form (DER et al., 1970; JORDAN and FRANKLIN, 1971) as applied by Mitchel. (1976), Canas and Mrtchell (1978), Canas et al. (1980), and CANAS and Correig (1981), Rayleigh-wave attenuation coefficients have been inverted to obtain an average $Q_{\beta}^{-1}$ model for the Atlantic Ocean. Love-wave attenuation coefficients have not been inverted due to the lack of data for periods less than $26 \mathrm{sec}$, and due also to the possible contamination of the shorter periods by higher mode energy. Rayleigh-wave data, used to determine the $Q_{\beta}^{-1}$ model, were obtained from 34 paths (Table 1) across the Atlantic and for a period range of 15 to $110 \mathrm{sec}$, therefore the $Q_{\beta}^{-1}$ model constructed using the Rayleigh data can be considered as a representative one for the Atlantic Ocean.

To invert the Rayleigh wave attenuation coefficients, the approximation of ANDERSON et al. (1965) was used. In the approximations it is assumed that $Q_{\beta}^{-1}$ is independent of frequency and that $Q_{\beta}^{-1}=(4 / 3)(\beta / \alpha)^{2} Q_{\alpha}^{-1}$, with $\alpha$ and $\beta$ being compressional and shear-wave velocities, and $Q_{\alpha}^{-1}$ the internal friction of compressional waves. The frequency-independent approach is a reasonable one for the period range used in this study, since only frequencies higher than $1 \mathrm{~Hz}$ are affected by the frequency-dependent approach (KANAMORI and ANDERSON, 1977; Minster, 1978; Sipkin and Jordan, 1979; ANDERson and Minster, 1980). 


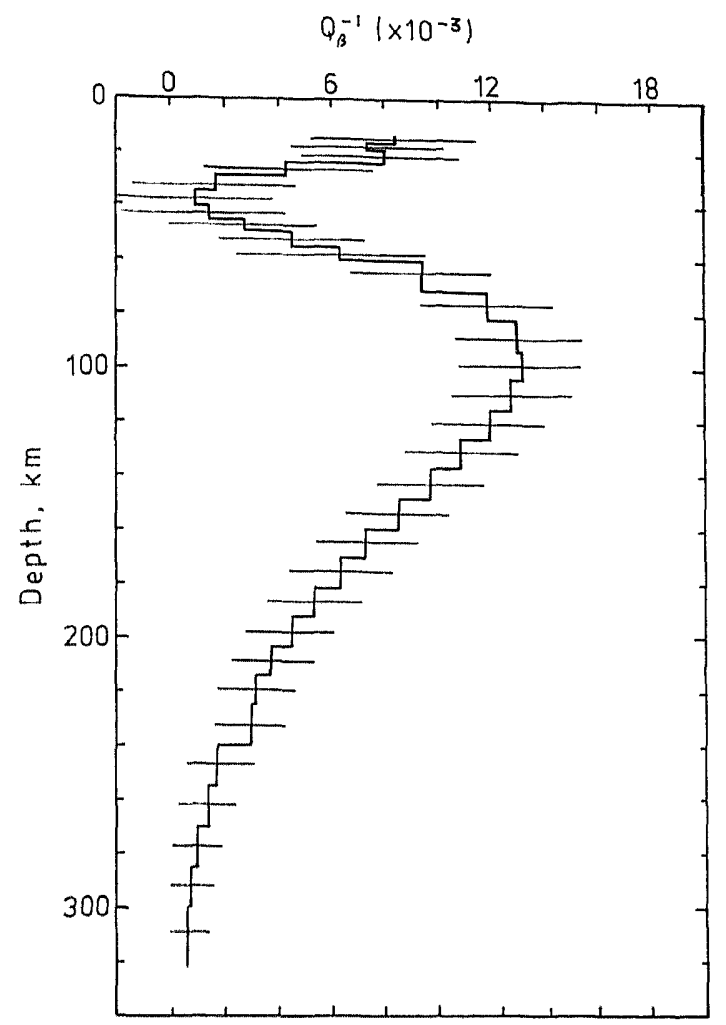

Fig. 4. $Q_{A}^{-1}$ model and standard deviations (horizontal bars) for the Atlantic obtained from the average Rayleigh-wave attenuation coefficients of Fig. 3 and Table 2.

The Earth model used to compute the partial derivatives for the inversion is the 8-3-2 model of SaITO and TAKEUChI (1966).

Figure 4 shows the average $Q_{\beta}^{-1}$ model for the Atlantic Ocean. Major features of this model are: (1) A clear low- $Q$ region is situated between depths of around 40 and $220 \mathrm{~km}$, (2) The maximum $Q_{\beta}^{-1}$ value $\left(\sim 13 \times 10^{-3}\right)$ occurs at $100 \mathrm{~km}$ depth, and (3) The resolving kernels calculated at several selected depths (Fig. 5), corresponding to the model in Fig. 4, become broader with increasing depth, indicating that the resolution is good at shallow depths, but becomes poorer at greater depths. Due to the poor resolution obtained, especially for depths greater than $200 \mathrm{~km}, Q_{\beta}^{-1}$ values at these depths must be interpreted only as tentative. Hopefully, studies of the attenuation for higher mode Rayleigh waves, presently in progress, may provide representative $Q_{\beta}^{-1}$ values for the poor resolved part of the Atlantic model (Fig. 4).

Figure 6 presents the theoretical attenuation coefficients obtained from the $Q_{\beta}^{-1}$ model in Fig. 4, together with the observed Rayleigh-wave attenuation coefficients. The agreement between observed and theoretical coefficients is a 


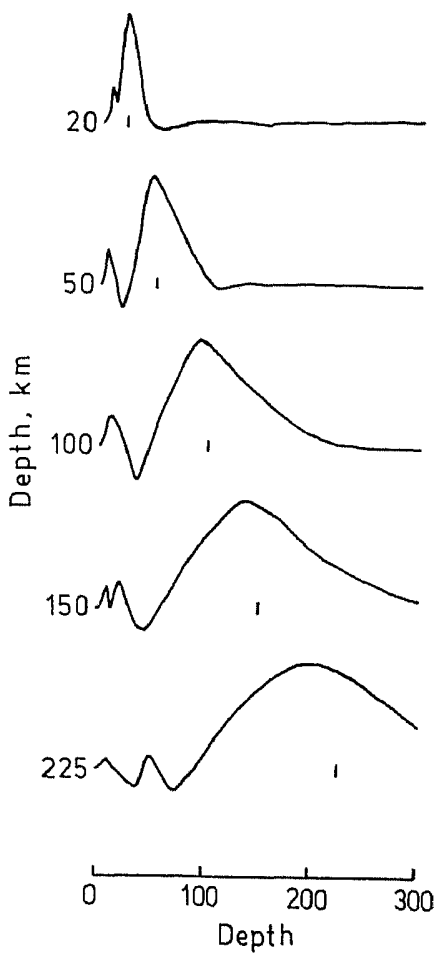

Fig. 5. Resolving kernels for the model of Fig. 4. The depth which each one is calculated is indicated by the vertical dash below each kernel.

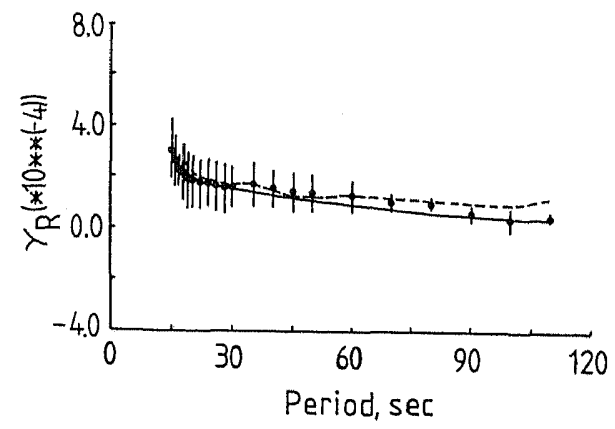

Fig. 6. Comparison between observed Rayleigh-wave attenuation coeficients (๑), and theoretical ones (solid line) corresponding to the $Q_{\beta}^{-1}$ model of Fig. 4. The dotted line represents the observed Rayleigh-wave attenuation coefficients for the Pacific (Mitchell et al., 1976).

reasonable one, indicating that the average internal friction model adequately explains the observed attenuation in the Atlantic Ocean. 


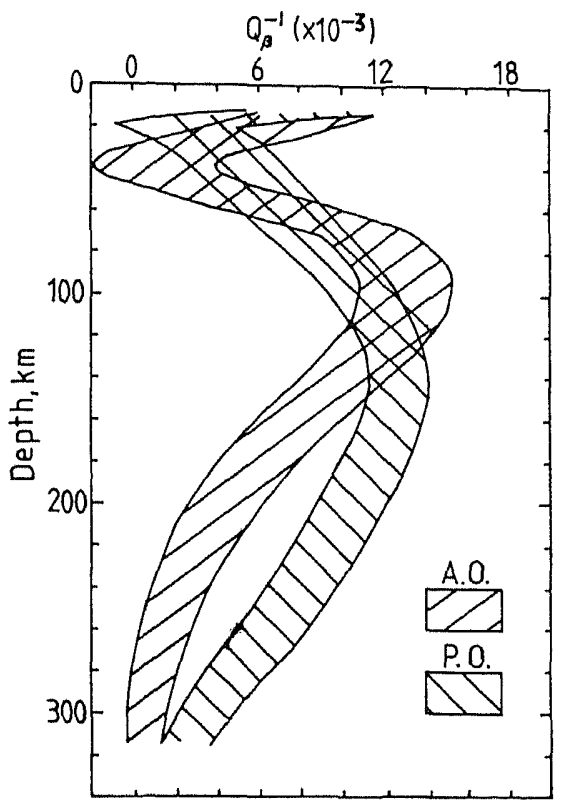

Fig. 7. Comparison between the $Q_{\beta}^{-1}$ model for the Atlantic Ocean and the one obtained for the Pacific (MrTCHELL, 1976).

\section{Comparison with Pacific Ocean Internal Friction}

MitChiLL's (1976) work includes an average $Q_{\beta}^{-1}$ model obtained from Rayleigh-wave attenuation coefficients (Fig. 6) corresponding to different paths that cover most of the Pacific with several of these paths crossing the East Pacific Rise. Since all the paths used in this study cross the Mid-Atlantic Ridge, the comparison will be done with Mrrchell's (1976) model.

Figure 7 shows the comparison between the $Q_{\beta}^{-1}$ models corresponding to the Atlantic and Pacific Oceans. Principle features are:

(1) Decrease in $Q_{A}$ values at depths near $40 \mathrm{~km}$ in the Atlantic model, and near $60 \mathrm{~km}$ in the Pacific model.

(2) The maximum $Q_{\beta}^{1}$ value being $\sim 13 \times 10^{-3}$ in the Atlantic model at $\sim 100 \mathrm{~km}$ depth, and $\sim 13,10^{-3}$ in the Pacific model at $\sim 130 \mathrm{~km}$ depth.

(3) Both the models show that, at depths of around $200-240 \mathrm{~km}$, the value of $Q_{\beta}^{\prime}$ have approximately the same values as those in the lithosphere. This result, although a tentative one because of the broad resolving kernels that the models exhibit at these depths (Fig. 5; Fig. 6 in Mrtchell, 1976), provides an estimation at which the bottom of the low- $Q$ zone may occur.

More recent studies in the Pacific (CANaS and Mitchell, 1978; Canas et al., 1980; CANAS and Correig, 1981) have shown that the $Q_{\beta}^{-1}$ models are a function of the oceanic age. Since the Atlantic average model obtained in this study is 
similar to the MrTCHELL's (1976) model, it may indicate that the distribution of the low- $Q$ zones under both the oceans may be approximately the same.

\section{Conclusions}

Average Rayleigh-wave attenuation coefficients for the Atlantic Ocean decrease from values of $3.04 \times 10^{-4} \mathrm{~km}^{-1}$ at $15 \mathrm{sec}$ to about $0.4 \times 10^{-4} \mathrm{~km}^{-1}$ at longer periods. Love-wave attenuation coefficients range from a maximum of $2.26 \times 10^{-4} \mathrm{~km}^{-1}$ to a minimum value of $0.92 \times 10^{-4} \mathrm{~km}^{-1}$ in the period range of 26 to $100 \mathrm{sec}$.

Inversion theory applied to the Rayleigh-wave attenuation coefficients indicates that a clear low- $Q$ zone exists in the upper mantle under the Atlantic Ocean, with the top and bottom of the low- $Q$ zone situated at depths near 40 and $220 \mathrm{~km}$, respectively.

Comparison between Atlantic and Pacific results indicates that similar low- $Q$ distributions may be expected in both the oceans.

I thank the Program of Cultural Cooperation between Spain and the United States of America, The Society of Exploration Geophysicists, and the Spanish Ministry of Universities and Investigation that supported my stay at Saint Louis University.

I gratefully acknowledge helpfull discussions with Brian Mitchell. Robert Hermann made his surface-wave dispersion programs available to me.

I thank also helpfull suggestions of the anonymous referees.

\section{REFERENCES}

ANDERSON, D. L. and J. B. Minster, The physics of creep and attenuation in the mantle (preprint), 1980.

Anderson, D. L., A. Ben-Menahem, and C. B. Archambeau, Attenuation of seismic energy in the upper mantle, J. Geophys. Res., 70, 1441-1448, 1965.

BACKus, G. E. and F. GrlberT, Numerical applications of a formalism for geophysical inverse problems, Geophys. J. R. Astron. Soc., 13, 247-276, 1967.

BAckus, G. E. and F. Gilbert, The resolving power of gross Earth data, Geophys. J. R. Astron. Soc., 16, 169-205, 1968.

BACKus, G. E. and F. GILBERT, Uniqueness in the inversion of innacurate gross Earth data, Philos. Trans. R. Soc., A266, 123-192, 1970.

Ben-Menahem, A., Observed attenuation and $Q$ values of seismic surface waves in the upper mantle, J. Geophys. Res., 70, 4641-4651, 1965.

Bravo, C. and A. Udras, Rayleigh wave group velocity dispersion in North Atlantic region, Geophys. J. R. Astron. Soc., 37, 297-304, 1974.

CANAS, J. A. and A. M. CoRreig, Modelo de fricción interna de las ondas de cizalla para las placas Nazca-Cocos, Geofisica Internacional, 1981 (in press).

CANAS, J. A. and B. J. MrTCHELL, Lateral variation of surface-wave anelastic attenuation across the Pacific, Bull. Seismol. Soc. Am., 68, 1637-1650, 1978.

CANAS, J. A. and A. Udias, Variación lateral de las velocidades de las ondas de cizalla en función de la edad del suelo oceánico del Pacífico, Anal. de Fis. de la R. S. E. de Fis. y Quim., 76, 278$284,1980$.

CAnas, J. A., B. J. Mrtchell, and A. M. Correig, $Q_{\beta}^{-1}$ models for the East Pacific Rise and the Nazca plate, in Mechanisms of Continental Drift and Plate Tectonics, ed. P. A. Davies and S. K. Runcorn, pp. 123-133, Academic Press, London, 1980. 
Der, Z. A., R. MASSE, and M. Landisman, Effects of observational errors on the resolution of surface waves at intermediate distances, J. Geophys. Res., 75, 3399-3409, 1970.

DraKe, L. A. and B. A. Bol.T, Love waves normally incident at a continental boundary, Bull. Seismol. Soc. Am., 70, 1103-1123, 1980.

DziEWONSKI, A., S. BLoCH, and M. LANDISMAN, A technique for the analysis of transient seismic signals, Bull. Seismol. Soc. Am., 59, 427-444, 1969.

Forsyth, D. W., A new method for the analysis of multi-mode surface-wave dispersion: Application to Love wave propagation in the east Pacific, Bull. Seismol. Soc. Am., 65, 323342,1975 a.

Forsyth, D. W., The early structural evolution and anisotropy of the oceanic upper mantle, Geophys. J. R. Astron. Soc., 43, 103-162, 1975 b.

Grrardin, N. and W. R. Jacoby, Rayleigh wave dispersion along Reykjanes Ridge, Tectonophysics, 55, 155-171, 1979.

Herrmann, R. B., Some aspects of band-pass filtering of surface waves, Bull. Seismol. Soc. Am., 63, 663-671, 1973.

JoRdan, T. H. and J. N. FrankLIN, Optimal solutions to a linear inverse problem in geophysics, Proc. Nat. Acad. Sci. Am., 68, 291-293, 1971.

KANAmORi, H. and D. L. Anderson, Importance of physical dispersion in surface wave and free oscillation problems; Review, Rev. Geophys. Space Phys., 15, 105-112, 1977.

Kausel, E. G., A. R. Leids, and L. Knoporf, Variations of Rayleigh wave phase velocities across the Pacilic Ocean, Science, 186, 139-141, 1974.

LeEDs, A. R., L. KNOPOFF and E. G. Kausel, Variations of upper mantle structure under the Pacific Ocean, Science, 186, 141-143, 1974.

Minster, J. B., Transient and impulse responses of a one-dimensional linearly attenuating medium-II. A parametric study, Geophys. J. R. Astron. Soc., 52, 503-524, 1978.

MitCHELL. B. J., Anelasticity of the crust and upper mantle beneath the Pacific Ocean from the inversion of observed surface wave attenuation, Geophys. J. R. Astron. Soc., 46., 521-533, 1976.

Mitchi:L, B. J. and M. LANdisman, Electromagnetic seismograph constants by least-squares inversion, Bull. Seismol. Soc. Am., 59, 1335-1348, 1969.

Mrtchill, B. J., L. W. L.tite, Y. K. YU, and R. B. HrirrmanN, Attenuation of Love and Rayleigh waves across the Pacific at periods between 15 and 110 seconds, Bull. Seismol. Soc. Am., 66, $1189-1201,1976$.

Ossinc, H. A., Dispersion of Rayleigh waves originating in the Mid-Atlantic Ridge, Bull. Seismol. Soc. Am., 54, 1137 $1196,1964$.

Sarto, M. and H. Taknuchr, Surface waves across the Pacific, Bull. Seismol. Soc. Am., 56, 1067$1091,1966$.

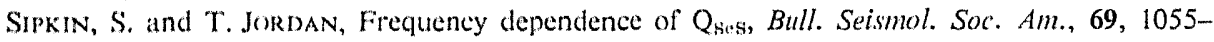
$1079,1979$.

Solomon, S. C., Shear wave attenuation and melting beneath the Mid-Atlantic ridge, J. Geophys. Res., 78, 6044-6059, 1973.

TSAI, Y. B. and K. Akr, Simultaneous determination of the seismic moment and attenuation of seismic surface waves, Bull. Seismol. Soc. Am., 59, 275-287, 1969.

WeIdner, D. J., Rayleigh wave phase velocities in the Atlantic Ocean, Geophys. J. R. Astron. Soc., 36, $105-139,1974$.

Yoshir, $T$., Regionality of group velocities of Rayleigh waves in the Pacific and thickening of the plate, Earth Planet. Sci. Lett., 25, 305-312, 1975.

YU, G. K. and B. J. MITCH:LL, Regionalized shear velocity models of the Pacific upper mantle from observed Love and Rayleigh wave dispersion, Cieophys. J. R. Astron. Soc., 57, 311-341, 1979. 